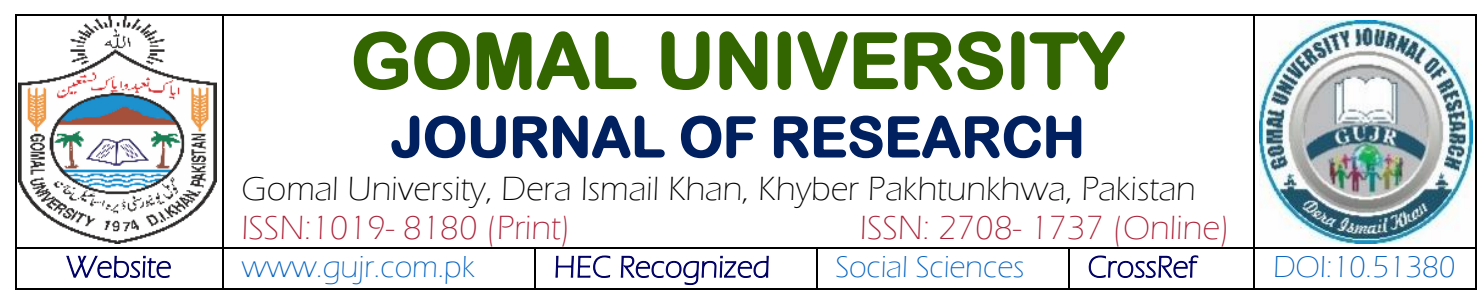

\title{
CLEAN GREEN PAKISTAN MOVEMENT: A WAY TO COMBAT THE CHALLENGES OF CLIMATE CHANGE
}

\author{
Imran Khan' \& Karim Haider Syed ${ }^{2}$ \\ 'Department of Political Science, Government Graduate College, Hafizabad Punjab, Pakistan \\ 2Pakistan Study Centre, University of the Punjab, Lahore, Pakistan
}

\begin{tabular}{|c|c|}
\hline KEYWORDS & ABSTRACT \\
\hline & \multirow{3}{*}{$\begin{array}{l}\text { Climate change has brought some challenges for the governments in the } \\
\text { world. Different governments in the world have adopted different policies } \\
\text { to face the challenges of climate change. Pakistan is one of most affected } \\
\text { nations by climate change and it has launched a complete program in the } \\
\text { clean and green Pakistan movement to counter these challenges. This is a } \\
\text { borderless issue and needed collective response along with the specific } \\
\text { one to combat these challenges. It is the matter of fact that Pakistan is a } \\
\text { developing nation with limited resources to combat the huge challenges } \\
\text { of climate change. Imran Khan as head of his political party PTI introduced } \\
\text { programs like the Billion tree tsunami in KPK in } 2014 \text { and later on won the } \\
\text { general elections of } 2018 \text { launched a ten billion tree tsunami campaign } \\
\text { and soon after made it part of the Clean Green Pakistan Movement. This } \\
\text { study focuses on the climate change effects on Pakistan and examines the } \\
\text { Clean Green Pakistan movement to counter the challenges of climate } \\
\text { change in Pakistan. } \\
\text { cac) }\end{array}$} \\
\hline Article History & \\
\hline $\begin{array}{l}\text { Date of Submission: } \\
\text { 24-08-2021 } \\
\text { Date of Acceptance: } \\
\text { 26-12-2021 } \\
\text { Date of Publication: } \\
31-12-2021\end{array}$ & \\
\hline Corresponding Author & \\
\hline $\mathrm{DOl}$ & \\
\hline
\end{tabular}

\section{INTRODUCTION}

Pakistan is among ten most affected countries by climate change. Since 1994, Pakistan's carbon emissions have increased and greenhouse gas emissions have been increasing every year at the rate of 123 percent per year. According to World Bank, if Pakistan does not take urgent steps to address the effects of climate change, it will become unbearable to live by 2030 (Abbas, Kalair, Khan \& Kalair, 2017). Despite being one of the weak countries battling climate threats, Pakistan continues to improve (Hussain, Butt, Uzma, 2020). It is noteworthy that when strong economies of the world are crumbling in wave of Coronavirus epidemic, Pakistan is continually working on its strategy and there is no pause in the green energy and tree plantation under the program of the clean and green Pakistan. At the government level, Imran Khan, as the Prime minister of Pakistan from the day of the inception of his government, has been giving special importance 
to the clean and green Pakistan program and projecting it as metaphor of his vision for a better world (Ahmed, Liu, Yousaf, Abbas, Ullah \& Ubaid, 2020). Clean and green Pakistan program is big and important part of Imran Khan's government strategy to combat the challenges of climate change.

This program needs recognition at the international level as the impact of the clean and green Pakistan program will not be limited to Pakistan. It is a matter of fact that climate change is a burning issue and research scholars have examined the role of different governments in the world to combat challenges of Climate change (Ali, Hassan \& Khan, 2009). During the review of the existing data, it was revealed that there is no research work on clean and green Pakistan program that is a part of the vision of Imran Khan's government. This work is important as a descriptive and analytical study on efforts of Imran khan's government to combat challenges of climate change (Husain, Mudasser, Sheikh \& Manzoor, 2005). The tree plantation campaigns under clean and green Pakistan program that is sensibly reflecting the vision of Prime Minister Imran Khan. It can be said a practical response from Pakistan being the responsible member of the international community to combat the challenges of the climate change. The intensity of the carbon in the atmosphere has reached about 419 parts per million in 2021 (CO2 Concentration, 2021).

Imran khan's government has set goals to reduce greenhouse gas emissions up to 20 percent in the next nine years by 2030. This intensity was not more than 300-350 in the history of the world. No event in the history of the civilized world can be cited as a difficult situation in this regard in the past. There is no way to reverse the climate change, but emergency measures can prevent further catastrophe. This study reviews the possible effects of the climate change and Imran Khan's government capability in addressing the associated problems. This study has been divided into some sections including the brief overview that is followed by the segment on climate tendencies in Pakistan. The following segment high spot the vulnerability of Pakistan to the climate change, trailed by a segment on the strategy of Imran Khan's government that has been or is being carried out in Pakistan to combat the challenge of climate change. Thus, in the last segment, the conclusion of the study is given which is one of the important sections of the study.

\section{Objectives}

Pakistan is among the most affected nations of climate change and in this regard the clean and green Pakistan program is a very important driver to counter the challenges of climate change. This study is important as it will help to examine certain objectives aligned with main theme of study: To highlight the intensity of challenges to Pakistan from climate change. To examine the strategy and vision of Imran Khan as prime minister of Pakistan to counter challenges of climate change.

\section{LITERATURE REVIEW}

There is are considerable studies that have been conducted on climate gauges and their tendencies in Pakistan. There are some studies on climate of Pakistan that explain the nature of challenges to Pakistan from the climate change (Ali, Hassan \& Khan, 2009; Husain, Mudasser, Sheikh \& Manzoor, 2005). After it, few studies have explained the policy of the government of Pakistan to deal with the phenomenon of climate change. According to these studies, the ordinary yearly temperature over Pakistan has increased by $0.6 \mathrm{C}$ in covenant with the worldwide trend since the end of the last century (Gadiwala and Sadiq 2008; Zahid \& Rasul 2009). Looking at the 
nature and rate of variation, though, had some differences throughout Pakistan and over time. This also explains that increase in temperature is high in northern Pakistan than in southern areas. The tendency recorded an upturn in average yearly precipitation in Pakistan depicted in the data of the last century (GCISC, 2010). It is assessed to have increased by 25 percent in the last one hundred years (Shakoor, Ayub \& Ayub, 2009). During the review of the literature, it is noted in the report of Maplecroft in its report put Pakistan on the16th rank among 170 nations and declared it the most vulnerable nation to the adverse effects of climate change (Maplecroft, 2010).

Chudhary (2017), in his work has discussed the issues relating to climate change in Pakistan in detail. He explains that world is currently experiencing changing weather, natural disasters. These are the issues that have engulfed the planet and nation without any distinction of race or color. It is also true that environmental issues go beyond political lines and boundaries drawn on the earth's chest (Ali, Hassan \& Khan, 2009). The polluted air does not matter whether it is holding the breath of Pakistani or an Indian. Toxic fumes from bad petrol, increasingly melting glaciers, floods, droughts, polluted rivers, and deforestation are just as big the threat to the rich countries as they are too poor ones. In this connection, the good thing is that they are not only aware of these dangers but also understand that poverty is a major cause of these problems (Eckstien, Hutfils \& Wings, 2019). Therefore, rich countries seem to make their lives easier by giving aid to poor countries in this regard, but behind the scenes, they are actually protecting themselves and this is also the case in Pakistan. In this connection, this work is very important as well as comprehensive on the climate change and its impact on the developing countries like Pakistan.

Hussian, et al. (2020), say that climate change destruction and damages may be seen all around world, but especially in South Asia, where populations are particularly vulnerable to climate change and climate change adaptability and management understanding is exceedingly poor. Pakistan's low adaptability is a result of country high poverty rate, insufficient market resources, effective resource depletion, and constant severe temperature events like varying temperatures, continuous flooding, melting ice caps, lake density, earthquakes, storms, hurricanes, landslides, water shortages, water scarcity, reptile epidemics, human healthcare problems, and temporary and healthy choices. This article is a sector-by-sector assessment of Pakistan's climate change mitigation and adaptation techniques in aforementioned industries, and associated economic consequences, which are estimated to be between $\$ 7$ and $\$ 14$ billion USD each year. According to results, government intervention is necessary for country's long-term growth, as evidenced by stringent resource liability and principles imposed in past for developing state-of-art climate policy.

\section{Hypothesis}

The clean and green Pakistan program has the potential to mobilize the people of Pakistan to promote the hygiene culture in Pakistan's society through various measures as examined in this study.

\section{RESEARCH METHODOLOGY}

A systematic examination of any research problem demands a specific model of research work. This is qualitative research that is based on researcher's papers, newspapers, official reports and documents, and books and data from websites. Secondary data analysis method is used to utilize the produced data on climate change in Pakistan. Descriptive research design is used to 
accurately and systematically describe situation that emerged from climate change in Pakistan. The current qualitative study is based on secondary data collected from reliable, official websites, together with worldbank.org, cleangreen.gov.pk, climate.nasa.gov. Descriptive research design is used to answer the research questions like what kind of challenges are being faced by Pakistan due to climate change? And what is response of Pakistani government to face challenges? The answers to these questions are important to provide relevant policy and response of government of Pakistan.

\section{Research Questions}

1. What kind of challenges are being faced by Pakistan due to climate change in the 2nd decade of the 21st century?

2. What is the vision of Prime Minister Imran Khan to counter the challenges posed by climate change to Pakistan?

\section{RESULTS \& DISCUSSIONS}

Climate change is graffiti that no country in the world can deny. In Global Environment Index released by German think tank Global Watch, Pakistan has been ranked among the five most endangered countries in world in December 2019. Not only Pakistan but whole region of South Asia is the target of negative effects of climate change. Seven of top ten countries in the world affected by climate change, including Pakistan, Bangladesh, Myanmar, Burma, Nepal, Philippines, Thailand and Vietnam are from Southeast and South Asia. According to meteorologists, Southeast Asia, and especially South Asia, is at greater risk than other parts of the world due to poverty, unemployment, growing population and dependence on seasonal agriculture (Abubakar, 2020). Most of the population of Southeast Asia and South Asia is dependent on agriculture and agriculture is dependent on seasons. While climate change has caused long-term and annual seasons to change drastically. Such kind of climate change in the region has made it an insecure area for such a huge population. "The majority of the region's human population lives on the banks of rivers due to agriculture and area is flooded due to heavy rains due to climate change, which makes the region vulnerable to the extraordinary effects of climate change (Shah et al., 2020)."

Seven out of ten countries affected by climate change in the world belong to this region and Pakistan is feared to be most affected in entire region. The Global Climate Index report of the global think tank of Germany has revealed that Pakistan was ranked eighth affected nation of climate change from 1998 to 2017, now it is on number five in the list of countries facing global warming due to the climate change from 1999 to 2018. So, Pakistan moved from eighth to fifth place in list of climate-affected countries. ("Climate Change-finance.gov.pk", 2020). The report further said that during this period, 10,000 deaths were reported due to the climatic events in Pakistan, and the country lost about four billion US dollars (Eckstien, Hutfils, \& Wings, 2019). Asian Development Bank has projected that Pakistan is annually facing an economic loss of up to $\$ 3.8$ billion due to climate change (Kiani, 2021). The region is prone to climate change due to its geographical location, sea level, and strong winds. Pakistan is affected country in entire region due to lack of forest area. City of gardens, Lahore, become a 'smog trap' due to heavy tree cutting campaign for construction of new transport roads (Khan, 2019). Karachi is becoming a 'heat trap' city (Ebrahim, 2020) and Islamabad is going to become a 'pollution trap' city (Khan, 2020). 
Under clean and Green Agenda of Prime Minister Imran Khan, projects like Billion Tree Tsunami and 10 Billion Tree Tsunami have not only raised awareness among the common man about forestry and afforestation across the country but have included him in these projects (Ahmad et al, 2020). Developed and developing countries are equally affected by these changes, but this is not a problem of countries, but of humanity, because climate change is affecting human life, people are still suffering and losing their lives. Given the negative impact of climate change on Pakistan's socio-economic conditions as whole, there is urgent need to create public awareness. It is a need for time to understand the impact of climate change on environment and economy so that Pakistan can overcome these difficult environmental conditions and secure sustainable future. Situation created by global climate change has now worsened and concrete and lasting measures are urgently needed to improve it. During its efforts for the improvement of climate, it also provided new employment opportunities to its people and emerged as a world leader in the efforts to improve climate. Pakistan's location and geography are generally considered to be its greatest strengths, but data about most affected nations of climate change has proved that Pakistan geography has become the greatest weakness and as Pakistan is in such geographical location that is facing severe climate change and is affected from its negative impact (Dimri et al, 2018).

Bhutan has forests on $25 \%$ of the total area while Pakistan has no forests on 3 to 4 percent. In addition, the dense population in Pakistan is causing problems. In the future, fertile land and water will be halved and the population will double. Thus, situation will get very serious. The government has taken number of steps in recent years to address the effects of climate change. These include the launch of the 'Clean and Green Pakistan Index' app to monitor large-scale tree planting, the use of plastic bags, and the sanitation situation in various cities. Pakistan has faced a number of natural disasters in the last ten years, including the worst floods, storms, rains, and heatstroke, while the country's largest city, Karachi, and has experienced the hottest weather and heatstroke. It also predicts that if effective strategies are not developed to tackle climate change, Pakistan could face drought in the coming years as it runs out of water reserves while rising temperatures have become a major threat to the survival of thousands of frozen membranes in Pakistan. Similarly, glaciers are melting rapidly due to extremely hot weather, which could lead to a drought in Pakistan, and this is not the end of the story. On the one hand, the shadow of drought is looming, on the other hand, due to climate change, the country's agriculture and agricultural production are also being affected. In this regard, meteorologists have warned that if timely precautions are not taken and no action is taken, drought could soon ensue.

Thirty percent of the world's forests are forested. The number of forests in Pakistan is barely three to four percent, and these forests are being cut down by the mafia. The amount of oxygen in the air is decreasing, while the amount of carbon dioxide is increasing. Smog and other similar pollutants are increasing exponentially. Forests play a pivotal role in climate change and at present, climate change is the biggest issue in Pakistan. Climate change is taking place due to deforestation. It is important to plant as many trees as possible. Imran Khan started the billion tree project is very useful for our future generations. Planting forests is like giving life to our future generations. If there are no trees, it will be difficult for our future generations to breathe. The polluted climate will cause diseases for the people of Pakistan and in this regard vision of Pakistani prime mister, Imran Khan is appreciable. In this connection, it is fact that to save future generations from the food crisis, Pakistan will have to invent new seeds for crops 
such as wheat and rice to adapt to the climate change. In this regard, climate change in Pakistan also threatens clean drinking water. The rising temperatures will melt glaciers in the country's northern mountains. According to the study by the International Panel on the Climate Change, global cold weather is likely to increase, while the duration of hot weather in Pakistan will also increase.

The GCISC study found that rising temperatures are having a negative impact on the crops in Pakistan, posing a serious threat to the country's food crisis. A large portion of the Pakistani government's financial resources are spent on dealing with and rehabilitating natural disasters caused by climate change, but Pakistan must take the necessary steps in this regard and it is not appropriate to make excuses for not being a major contributor to air pollution. Pakistan needs to take steps to improve the economic situation of the people because there is a strong link between poverty and climate change. People are migrating to cities for economic improvement and this process is affecting the urban environment. Pakistan's average temperature will rise in coming decades, relative to global warming. It will happen much faster (Performance Report 2019-20, 2020). Tree plantation campaign is very important to repair the ozone layer. Natural greenhouse gases in atmosphere accelerate the greenhouse effect. Activities such as industrial processes, agricultural activities, deforestation, and use of fossil energy resources exceed the greenhouse gas emissions and rising temperatures in lower and middle regions are major cause of global warming. In addition, the concentration of aerosols accumulated in the troposphere as a result of use of fossil energy sources changes the cloud volume and reflection properties. It forcibly produces negative radiation in the tendency to cool the climate. In addition, volcanic ash particles reflect radiation of a small wave from the sun, which cools the troposphere and earth.

Climate change is posing new challenges to humans and wildlife, with heavy rains and floods and floods causing irreparable damage to agriculture, which could lead to serious problems such as food shortages. Many countries are living in a state of starvation due to drought and developing countries are facing the worst of food shortages, which have been exacerbated by high food purchases. And essential commodities are becoming out of reach of the common man, leading to fears of civil wars between humans over food. The billion Tree Tsunami was launched by Imran khan as chairman of his party PTI (Pakistan Tehreek Insaf; Pakistan Movement for Justice) in the KPK (Khyber Pakhtunkhwa) when his party formed the first government in this province after the 2013 general elections. Billion Tree Tsunami was launched as a response to climate change and international global warming. Pakistan was one of the top seven most dangerous countries in terms of the global warming where the rising temperatures are causing climate change. Pakistan in three years planted trees on the largest area of about 348,00o Hectares. In this connection, this work of the PTI's government in KPK attracted Inger Anderson, Director General of IUCN and the leading Danish environmentalist, who praised the Pakistan for this said greates work ("Pakistan's Billion Tree Tsunami restores 348,00o plus hectares of forests and degraded land to surpass Bonn Challenge commitment", 2017).

The survey report revealed that the trees planted under the project across the province have been planted 100 percent correctly (Naeem, 2021). After it, in 2018 Imran Khan won general elections and become prime minister of Pakistan and announced five years' 10 billion tree Tsunami projects and allocated US\$680 Million for the project in September 2018. He spread this project all over the Pakistan and asked his party workers and provincial governments to 
participate in this project and renamed it the Plant for Pakistan project. In this tree planting campaign, the government has not only provided loans to the people for setting up nurseries in each province but has also entered into agreements to guarantee the purchase of plants from them. Imran Khan launched a clean and green project on October 13, 2018, to include other areas of action to reduce pollution and counter the challenges of climate change. Clean and green Pakistan has following major programs; clean drinking water, tree plantation, sanitation, solid waste management, hygiene. When in 2019 COVID started to spread in Pakistan COVID was also included in clean and green Pakistan project (Clean Green Pakistan, 2021). Under clean drinking water program, Pakistan is committed to giving the people of Pakistan access to adequate and sanitation services, which are dynamic for, disease prevention, hygiene, and their health.

The second most important and flagship program under the clean and green Pakistan project is tree plantation. This program has started to increase the forest land cover in Pakistan up to the international standard of 25 percent which currently only has 5 percent. The program is being implemented in nearly one hundred districts of Pakistan under the supervision of the Ministry of Climate Change. Wildlife Departments are leading the program to achieve the target of ten billion trees over time period of 5 years. This program can result in the restoration of wildlife resources, reduction in temperature. The tree plantation campaign is one of most important parts of the clean and green Pakistan project. There were more than forty officially counted forest areas in Lahore in 1947, but now they are less than half. The clean and green Pakistan campaign is making all possible to grow forests that will be helpful to counter the challenges of climate change (Aslam, 2021). In the clean and green campaign, the focus of the government is on the tree plantation campaign. Most of the tree planting has been done in forested areas. The forests of Pakistan are divided into three regions under this program. The first is the Central Southern Forest Region which includes Peshawar, Mardan, Kohat, and other areas. The second is Northern Forest Region which includes Abbottabad Haripur, Kohistan Buner area. The third is the Northern Malakand Region which includes the areas of Dir, Swat, and Chitral (Haq, 2021).

The third program in clean and green Pakistan movement is hygiene program. This program is launched to introduce the importance of hygiene in the society of Pakistan, so a better health standard can be achieved. Looking at the poor sanitation facilities in Pakistan, the government included the sanitation in clean and green Pakistan movement. Because poor sanitation harms the health of people and also gives birth to several concerns related to the environment and socio-economic condition. Insufficient dumping of human excreta and personal hygiene are connected with a variety of diseases comprising diarrheal diseases, polio, jaundice, malaria, typhoid, and cholera, and dengue viral fever. In this connection, the fourth important part of CGP is Solid Waste Management. It is also an important program of the Clean and Green Pakistan Movement that is about solid waste as it is the useless material that is thrown out for the reason that it is no longer useful. Pakistan must be working properly on some challenges to climate change including the reduction of Methane pollution. In this regard, the report nullifies any remaining debate on the urgent need to reduce methane pollution, especially in sectors such as oil and gas, where the available reductions are faster and more economical" (Krupp, 2021).

Under the solid waste management program, every household including businesspersons and commercial organizations embraced solid waste management to overcome the issues of health 
and environment. Methane is produced through the belching of cattle, sheep, and goats, as well as manure management and rice farming. Nitrous oxide is mostly produced in agricultural soils as a result of the use of synthetic fertilizers, farmyard manure, and crop waste mixes. In 2019 burning fossil gas, coal, and oil each emitted around 80 million tons as Energy Green House Gases is carbon dioxide. It has been argued that tougher anti-pollution efforts in Pakistan could include activities to reduce GHG emissions, such as raising the tariff on motor fuels. In 2020, Pakistani Prime Minister Imran Khan stated that no further coal-fired power plants would be permitted. (Pakistan faces unexpected dilemma: Too much electricity, 2021). Every year more than 40,000 innocent children in Pakistan fall prey to diseases due to environmental pollution. Pollution, hepatitis and other deadly diseases are spreading due to discharge of sewage water in rivers and streams. Solid waste management recycle and treat polluted water for better treatment of waste.

Prime Minister of Pakistan Imran Khan has the vision to make the country cleaner and greener by eliminating pollution. He urged the nation to participate in the clean and green Pakistan program to make it successful, regardless of affiliation with any political party because the health of people and a clean environment are of the utmost importance to the future generation of Pakistan (Raza, 2018). Prime Minister Imran Khan has introduced the eco-friendly vision and adopted the policy to reduce the dependency on energy from coal and inaugurated the construction of new Dams and renewable energy projects in Pakistan (Baloch \& Saud, 2018). The latest inclusion of the project in CGP is the CGP champion. It is important to note that the clean and green champions are the latest program that will be included in the clean and green program in which mobile applications will be developed to engage the young people in the CGP movement. The volunteers will be asked to get register in the program and they will be asked to help the government institutions in the CGP movement and raise awareness among the people to cooperate and participate in the project to make Pakistan a clean and green country (Aslam, 2021).

\section{CONCLUSION}

Despite all the unfavorable conditions, Clean and Green Pakistan Movement is moving forward. This project has become inspiring for the other nations as United Nations and institutions like the World Economic Forum have warmly appreciated Pakistan's commitments under CGPM. Many other countries, including South Africa, Bangladesh, and Saudi Arabia, have launched similar projects in their countries. Pakistan must consider environmental sustainability over the long term, several of decisions it could take to manage and start reversing environmental damage and mitigate climate change would have tangible benefits and would be especially beneficial to the poorest, who are most vulnerable. Because it is a mass revolution that focuses on behavioral change to build a push for better environmental health. As part of the Clean Green Pakistan project, people are being educated and engaged in environmental management over pollution and green development awareness campaigns. With environmental decentralization, Pakistan has incentive to optimize devolution by distinguishing and revising federal, provincial, and local roles and responsibilities, as well as determining which policy actions should be taken by whom and how to integrate it all, given threshold and efficiency issues. In this connection, the possible effects of the Clean and Green Pakistan program on climate change identified in this paper will become visible with time. As time is needed to grow the trees, build renewable energy projects, and adoption of modern techniques. Thus, Pakistan is one of the developing 
nations that is facing energy crisis and challenges of food and water crisis due to climate change effects.

\section{Suggestions}

Clean and Green Pakistan project is a difficult task but can be achieved through modification in the behavior of the people of Pakistan. If one family grows one plant, there are about 32 million families in the country and they can grow 32 million trees in one year. People can also plant a tree at their wedding or at the birth of a child to nurture it as a memento. People can also sell dry waste such as newspapers, envelopes, trash, boxes, and other such items and make them part of the recycling system. Just having an extra trash basket at home can lay the groundwork for a big change. People should establish a committee at the street level, to make sure that the cleaning staff does their job properly, and that the residents of the neighborhood do not throw extra garbage in the street after cleaning their homes. In this connection, two separate bins (dry and wet) can be installed in each street which will facilitate the government in its work. People should develop short plantation beds in front of houses, as it is good for mental and physical health.

The teacher community should play a role to teach the students to grow plants and telling them that cleanliness is vital for their health. So that they can keep home, school, and neighborhood clean. If a child throws garbage at school, teach them lovingly that it is wrong to do so. Only this training of teachers will be able to create a mentally organized nation in the future. With simple steps, people should save the waste of water. They should use the water from the washbasin in the flush tank by making minor changes through plumber. In building a new home, a filtered plant should be used and the used water can be utilized for gardening. It is suggested at the end of this study that Pakistan has such a landscape that can help it to work on new ideas in the field of forestry. It should enhance capacity of renewable energy and should adopt international protocols on environmental protection. Pakistan should seek help from developed world to reduce the pollution in air by utilizing the new technologies in agricultural, industrial, and transport sectors.

\section{REFERENCE}

Abbas, N., Kalair, A., Khan, N., \& Kalair, A. R. (2017). Review of GHG emissions in Pakistan compared to SAARC countries. Renewal Sustainable Energy Revision, 80, 990-1016. https://doi.org/10.1016/j.rser.2017.04.022.

Abubakar, S. M. (2020). Pakistan 5th most vulnerable country to climate change, reveals Germanwatch report. Retrieved from https://www.dawn.com/news/1520402.

Ahmed, R., Liu, G., Yousaf, B., Abbas, Q., Ullah, H., \& Ubaid, M., (2020). Recent advances in carbon-based renewable adsorbent for selective carbon dioxide capture and separation -A review 242.

Ali, G., Hassan, S., \& Khan, A. M. (2009). Climate Change: Implications and Adaptation of Water Resources in Pakistan, Research Report No.GCISC-RR-13. Global Change Impact Studies Centre, Islamabad.

Aslam, A. M. P. (2021). The Clean and Green Pakistan . The Nawa e Waqat, Lahore, Pakistan.

Baloch, M. A., \& Suad, S. (2018). Role of renewable energy and nonrenewable energy consumption on EKC: Evidence from Pakistan. 9461-9473. 
Butcher, M. (2021, August 09). UN's IPCC report on climate change sounds 'code red' for planet. Retrieved August 13, 2021, from https://techcrunch.com/2021/08/09/uns-ipcc -report-on-climate-change-sounds-code-red-for-planet/.

Chudhary, Q. (2017) Climate Change Profile of Pakistan. Mandaluyong: Asian Development Bank.

D. W. (2021) (www.dw.com). UN report author and climate expert Friederike Otto talks to DW: DW: 09.08.2021. Retrieved August 12, 2021, from https://www.dw.com/en/un-reportauthor-and-climate-expert-friederike-otto-talks-to-dw/av-58810649.

Delmotte, V. M. (2021, August 09). Climate change widespread, rapid, and intensifying - IPCC [EN/AR/RU/ZH]-World. Retrieved August 12, 2021, from https://reliefweb.int/ report/ world /climate-change-widespread-rapid-and-intensifying-ipcc-enarruzh.

Dimri, A. P., Kumar, D., Choudhary, A., \& Maharana, P. (2018). Future changes over the Himalayas: maximum and minimum temperature. Glob Planet Change, 162, 212-234. https://doi.org/10.1016/j.gloplacha.2018.01.015.

Ebrahim, Z. (2020). Karachi turns into heat trap. Retrieved from https://www.thethirdpole .net /en/climate/karachi-turns-into-heat-trap/.

Eckstien, D., Hutfils, M. L., \& Wings, M. (2019). GLOBAL CLIMATE RISK INDEX 2019 (pp. 4-38, Rep.). Bonn: Germanwatch e.V.

Gadiwala, M. S., \& Sadiq, N. (2008). The apparent temperature analysis of Pakistan using biometeorological indices. Pakistan Journal of Meteorology, 4(8):212-219

Haq, R. (2021). Imran Khan Vision clean Pakistan, Roznama Express. Lahore, Pakista.

Husain, S. S., Mudasser, M., Sheikh, M. M., \& Manzoor, N. (2005). Climate change and variability in mountain regions of Pakistan: implications for water and agriculture. Pakistan Journal of Meteorology 2(4):113-120 ICIMOD (2015) Action for Adaptation: bringing climate change science to policy makers. http://www.icimod.org/?q=18559.

Hussain, M., Butt, A. R., \& Uzma, F. l. (2020). A comprehensive review of climate change impacts, adaptation, and mitigation on environmental and natural calamities in Pakistan. Environ Monit Assess 192, 48. https://doi.org/10.1007/s10661-019-7956-4.

Khan, A. S. (2020, September 10). Islamabad 7 th most polluted city of Pakistan. Retrieved from https://www.thenews.com.pk/print/712668-islamabad-7th-most-polluted-city-ofpakistan.

Kiani, K. (2021, May 19). 'Climate change to cost Pakistan $\$ 3.8 b n$ yearly'. Retrieved from https://www.dawn.com/news/1624382

Krupp, F. (2021, August 11). Opinion: Frightening new climate report also holds the seeds of hope. Retrieved August 12, 2021, from https://edition.cnn.com/2021/o8/10/opinions/ frightening-climate-change-report-fred-krupp/index.html.

Leeds, U. O. (2021, August 09). Climate change 'widespread, rapid and intensifying'. Retrieved August 12, 2021, from https://www.leeds.ac.uk/news-environment/news/article/4890/ climate-change-widespread-rapid-and-intensifying.

List of polling stations for a constituency of Election to the National Assembly of the NA-87 Hafizabad-I. (2018, May 13). Retrieved from https://www.ecp.gov.pk/Documents Lgeneralelections2018/draft polling scheme/Punjab/Hafizabad/Hafizabad NA.pdf.

Maplecroft. (2010). Global risks portfolio and services-Maplecroft's climate change risk Atlas Retrieved August 12, 2021, from http://www.maplecroft.com/about/ news/climate_ change_risk_list_highlights_vulnerable_nations_and_safe_havens_05.html.

Meinshausen A/Prof., $\bar{M}$. (2021, August 10). IPCC says Earth will reach temperature rise of about $1.5^{\circ} \mathrm{C}$ in around a decade. But limiting any global warming is what matters most. 
Retrieved August 12, 2021, from https://theconversation.com/ipcc-says-earth-willreach-temperature-rise-of-about-1-5-in-around-a-decade-but-limiting-any-global-warm ing-is-what-matters-most-165397.

Naeem, P. (2021). The Clean and Green Vision. The Roznama Jang, Rawalpindi.

Pakistan faces an unexpected dilemma: Too much electricity. (2021, February 25). Retrieved August 10, 2021, from https://www.eco-business.com/news/pakistan-faces-anunexpected-dilemma-too-much-electricity/.

Pakistans Billion Tree Tsunami restores 348,00o plus hectares of forests and degraded land to surpass Bonn Challenge commitment. (2017, August 15). Retrieved from https:// www.iucn. org/id/node/28962.

Performance Report 2019-20 (pp. 1-16, Rep.). (2020). Islamabad: The Global Change Impact Studies Centre.

Shah, S. M., Mustaffa, Z., Teo, F. Y., Imam, M. A., Yusof, K. W., \& Al-Qadami, E. H. (2020). A review of the flood hazard and risk management in the South Asian Region, particularly Pakistan. Scientific African, 10. doi:10.1016/j.sciaf.2020.e00651.

Shakoor, M. T., Ayub, S., \& Ayub. Z. (2012). Dengue fever: Pakistan's worst nightmare, World Health Organization (WHO) South-East Asia. Journal of Public Health, 1(3):244-247

Written by Rina Saeed Khan, W. (2019, January 11). How Pakistan is tackling its air pollution. Retrieved from https://www.weforum.org/agenda/2019/01/as-lahore-chokes-on-winter -smog-pakistan-moves-to-cut-air-pollution.

Zahid, M., \& Rasul G. (2009). Rise in summer heat index over Pakistan. Pakistan Journal of Meteorology, 6(12):123-126. 